\title{
SPECTROSCOPIC CHARACTERIZATION OF ETHYLENEDIAMINE- DI(o-HYDROXYPHENYL)ACETIC ACID AND ITS COMPLEXES WITH LANTHANIDE(III) IONS
}

\author{
Z. Hnatejko, S. Lis and M. Elbanowsio \\ Department of Rare Earths, Faculty of Chemistry, Adam Mickiewicz University \\ Grunwaldzka 6, 60-780 Poznań, Poland
}

Binding properties of ethylenediaminedi(o-hydroxyphenyl)acetic acid (EIIPG) with lanthanide(III) ions were studied using spectroscopic methods. Luminescence intensity and lifetime of the $\mathrm{Tb}$ (III) ion were measured in a wide $\mathrm{pH}$ range in order to characterize the Ln-EHPG complexation. The calculated hydration number of the Tb-EHPG system proved the replacement of six water molecules by the EHPG ligand in the inner coordination sphere of $\mathrm{Tb}(\mathrm{III})$. Energy transfer from $\mathrm{Tb}(\mathrm{III})$ to $\mathrm{Eu}$ (III) in the $\mathrm{Tb}$ (III)-EIIPG-Eu(III) system indicated an existence of only monomeric form of the Tb-EHPG complex. Analysis of the ${ }^{1} \mathrm{H}$ NMR and FTIR spectra of the EHPG ligand and its complexes with lanthanide(III) ions confirmed the hexadentate manner of EHPG complexation with the lanthanides. The system of Dy(III)-EIIPG, showing a linear dependence of luminescence intensity $\left(\lambda_{\mathrm{cm}}=578 \mathrm{~nm}\right)$ of $\mathrm{Dy}(\mathrm{III})$ on its concentration, in the range of $3.3 \times 10^{-7}$ to $1 \times 10^{-5} \mathrm{~mol} \cdot \mathrm{l}^{-1}$, can be applied for spectrofluorimetric determination of Dy(III).

PACS numbers: 78.55.-m, 42.62.Ilk, 78.40.Ha, 78.40.-q

\section{Introduction}

The spectroscopic properties of trivalent lanthanides have attracted much attention in studying a variety of complexes in solution [1-3]. Ion luminescence and absorption (in the UV-visible and the near IR region) of certain lanthanide(III) ions make these ions useful in the characterization of lanthanide complexation in solution [2-4]. The luminescence intensity and lifetime of $\mathrm{Eu}(\mathrm{III})$ and $\mathrm{Tb}(\mathrm{III})$ ions have been used to gain information on the composition and structure of the first coordination sphere of these ions in a variety of systems [3-6]. Studies using ${ }^{1}$ II NMR have been valuable to elucidate the nature and structures of $\mathrm{La}$ (III) or $\mathrm{Lu}(\mathrm{III})$ complexes [7]. 
Previously we reported the use of Eu(III) lifetime measurements to identify the residual hydration of the $\mathrm{Eu}(\mathrm{III})$ ion in aminopolycarboxylate complexes [8] and to characterize the bonding properties of the nitrogen, oxygen and sulfur donors to lanthanide ions with dicarboxylate ligands [9].

This paper is concerned with spectroscopic characterization of ethylenediaminedi(o-hydroxyphenyl)acetic acid (EIIPG) and its complexation study with lanthanide ions. Complexation of EIIPG with rare earth(III) ions were studied using pH-potentiometric and spectrophotometric methods [10] and potentiometric, luminescence intensity and lifetime measurements [11]. We report a study of hydration of the $\mathrm{Tb}(\mathrm{III})$ ion using the $\mathrm{Tb}$ (III) luminescence intensity and lifetime measurements, in the Tb-EHPG system, and energy transfer from $\mathrm{Tb}$ (III) to $\mathrm{Eu}$ (III) in the Tb(III)-EHPG-Eu(III) system. The ${ }^{1}$ II NMR and FTIR spectra of the EHPG ligand and its complexes with lanthanide(III) ions are analysed in order to explain the binding properties of the ligand and a possibility of the Dy(III)-EIIPG system for the spectrofluorimetric determination of $\mathrm{Dy}(\mathrm{III})$ is tested.

\section{Experimental}

\subsection{Solutions}

The reagent grade of the ethylenediaminedi(o-hydroxyphenyl)acetic acid was obtained from Sigma and used as received. Solutions of $\mathrm{Tb}\left(\mathrm{ClO}_{4}\right)_{3}, \mathrm{Eu}\left(\mathrm{ClO}_{4}\right)_{3}$ and $\mathrm{La}\left(\mathrm{ClO}_{4}\right)_{3}$ were prepared by dissolving $\mathrm{Tb}_{4} \mathrm{O}_{7}, \mathrm{Eu}_{2} \mathrm{O}_{3}$ and $\mathrm{La}_{2} \mathrm{O}_{3}$ (spectral pure, made in our laboratory), respectively, in hydrochloric acid. Aliquots were added to solutions of the ligand such that the concentration of $\mathrm{Eu}(\mathrm{III})$ was $0.01 \mathrm{~mol} \cdot \mathrm{l}^{-1}$ and all solutions had a final ionic strength $0.1 \mathrm{~mol} \cdot \mathrm{I}^{-1} \mathrm{NaClO}_{4}$. The pH values of the solutions were adjusted by addition of aliquots of standard solutions of $\mathrm{NaOH}$ or of $\mathrm{HCl}$. For the studies in $\mathrm{D}_{2} \mathrm{O}$ (purity $>99.8 \%$ ), aliquots of $\mathrm{TbCl}_{3}$ solution were evaporated to dryness, followed by dissolution in $\mathrm{D}_{2} \mathrm{O}$. This procedure was repeated four times. Solutions of $\mathrm{NaOD}$ and $\mathrm{DCl}$ were used to adjust the $\mathrm{pD}$ values in these systems. During handling, the experimental vessels were protected with parafilm to avoid absorption by the samples of $\mathrm{H}_{2} \mathrm{O}$ from the air. Solutions of EIIPG and $\mathrm{La}\left(\mathrm{ClO}_{4}\right)_{3}$ for NMR studies in $\mathrm{D}_{2} \mathrm{O}$ were prepared in the same way. The solid Eu-EIIPG- complex was prepared in a reaction of EHPG with $\mathrm{Eu}\left(\mathrm{ClO}_{4}\right)_{3}$ from equimolar water solutions at $\mathrm{pII} \approx 11$.

\subsection{Equipment}

The $\mathrm{Tb}(\mathrm{III})$ corrected luminescence spectra were registered using Perkin-Elmer MPF-3 spectrofluorimeter and the exciting wavelength was $368 \mathrm{~nm}$.

The luminescence lifetime measurements of $\mathrm{Eu}(\mathrm{III})$ were carried out with the use of the detection system described earlier [12] consisting of a nitrogen laser (KB6211) and a tunable dye laser. The luminescence decay curves observed in this work could be analysed by a single exponential relation (semilogarithmic plots of the luminescence intensity versus time were linear, providing the decay constants).

The ${ }^{1}$ II NMR spectra were recorded using a Gemini 300 VT Varian spectrometer operating at $300 \mathrm{MHz}$ at room temperature. The chemical shift values are in $\mathrm{ppm}$ (with accuracy of $\pm 0.01 \mathrm{ppm}$ ) in $\delta$ scale relative to DSS. 
The IR spectra were obtained by means of FTIR Bruker JFS $113 \mathrm{v}$ spectrophotometer, and the samples $(1.5 \mathrm{mg})$ were prepared in $\mathrm{KBr}(200 \mathrm{mg})$.

\section{Results and discussion}

The EHPG ligand forms a metal-ligand 1:1 complex [10,11]. Schematic presentation of the EIPPG ligand is shown in Fig. 1.<smiles>O=C(O)C(=O)NCCNC(C(=O)O)c1ccccc1O</smiles>

Fig. 1. Schematic presentation of the EIIPG ligand.

The ligand has six potential ligating groups: two carboxylate groups, two phenolate oxygens and two amino nitrogens. Lanthanide ion binding to EHPG is of particular interest as an analogue of lanthanide binding to proteins, since the ligating groups of EIIPG are similar to those in many proteins [11].

The luminescence intensity $\left(I_{\text {lum }}\right)$ of the most intense band for $\mathrm{Tb}(\mathrm{III})$ at $545 \mathrm{~nm}$, corresponding to the ${ }^{5} D_{4} \rightarrow{ }^{7} F_{5}$ transition, and $\mathrm{Tb}$ (III) luminescence lifetime $(\tau)$ in the system containing Tb:EIIPG $=1: 1$, depending on the $\mathrm{pH}$ value was investigated. A plot of the $I_{\text {lum }}$ and $\tau$ dependence on varying $\mathrm{pII}$ (in the pH range 5-12) is shown in Fig. 2. The data plotted in Fig. 2 demonstrate the strong pII dependence of terbium luminescence intensity in the Tb-EHPG- complex. The increasing intensity follows the binding of all the ligand moieties. The extent of direct Tlb-phenolate binding and Tb-nitrogen donor binding increases with in-

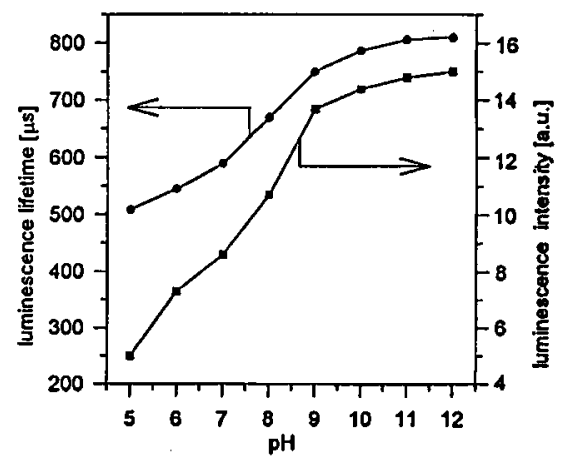

Fig. 2. Luminescence intensity and lifetime of $\mathrm{Tb}(\mathrm{III})$ ion in the Tb-EHPG system as a function of $\mathrm{pH}$. 
creasing $\mathrm{pI}$, and the terbium luminescence intensity also increases with increasing pII.

The luminescence lifetime of $\mathrm{Tb}(\mathrm{III})$ in complexes with the EHPG ligand has been measured in $\mathrm{II}_{2} \mathrm{O}$ and $\mathrm{D}_{2} \mathrm{O}$ solutions and used to calculate the number of water molecules coordinated to $\mathrm{Tb}(\mathrm{III})$ in the Tb-EIIPG- complex.

The number of water molecules coordinated to $\mathrm{Tb}(\mathrm{III})$ in this system was determined from the reciprocal excited-state lifetime, $\tau^{-1}$, separately in $\mathrm{H}_{2} \mathrm{O}$ and $\mathrm{D}_{2} \mathrm{O}$ solutions. The number of coordinated water molecules, $n_{\mathrm{H}_{2} \mathrm{O}}$, has been calculated from Eq. (1), regarding the contribution of the N-II vibration $[4,13,14]$ :

$$
n_{\mathrm{H}_{2} \mathrm{O}}=4.2\left(\tau_{\mathrm{II}_{2} \mathrm{O}}^{-1}-\tau_{\mathrm{D}_{2} \mathrm{O}}^{-1}\right) .
$$

The total coordination number of the $\mathrm{Tb}$ (III) ion is 8 or $9[2,3,11]$, and in this study it was found to be 8.7 . The hydration number of the Tb-EIIPG- $(1: 1)$ complex depends on pII solution. The obtained results show that the Tb-EHPGcomplex has less than five water molecules of hydration in pII $<6$ region and less than three water molecules of hydration when $\mathrm{pII}>9$. This indicates that EIIPG coordinates as a hexadentate ligand in the basic region of pII, where its all potentially ligating groups are deprotonated.

In the ${ }^{1}$ II NMR spectrum of EIIPG solution in $\mathrm{D}_{2} \mathrm{O}$ there are observed signals of nonlabilc protons of methylene, methine groups and aromatic ring protons, denoted in Fig. 1 as $a, b, c$ and d, respectively, in the dependence on $\mathrm{pD}$. An increase in $\mathrm{pD}$ causes a successive dissociation of four $\mathrm{D}^{+}$ions of the EHPG functional (carboxylic and phenolic) groups (see Table I). This dissociation contributes to the increase in the electron density at nonlabile protons, which is observed as the decrease in their chemical shift values. Dependence of chemical shifts of the ${ }^{1} \mathrm{II}$ NMR signals of nonlabile protons of EIIPG in $\mathrm{D}_{2} \mathrm{O}$ solutions on $\mathrm{pD}$ is shown in Fig. 3. The formation of the La-EIIPG- complex was found from the $\mathrm{pD}$ de-

\section{TABLE I}

Calculated values of the Stern-Volmer quenching constants $\left(K_{\mathrm{SV}}^{\phi}\right.$ and $\left.K_{\mathrm{SV}}^{\tau}\right)$ and the intramolecular association constant $\left(K_{\mathrm{C}}\right)$ as a function of $\mathrm{pH}$ in solution of the Tb-EIPG ${ }^{-}$complex.

\begin{tabular}{c|c|c|c}
\hline \hline $\mathrm{pH}$ & $K_{\mathrm{SV}}^{\phi}$ & $K_{\mathrm{SV}}^{\tau}$ & $K_{\mathrm{C}}$ \\
\hline 6.0 & 626 & 620 & 4 \\
7.0 & 567 & 497 & 73 \\
8.0 & 492 & 379 & 93 \\
9.0 & 288 & 284 & 15 \\
10.0 & 239 & 148 & 86 \\
11.0 & 370 & 264 & 97
\end{tabular}




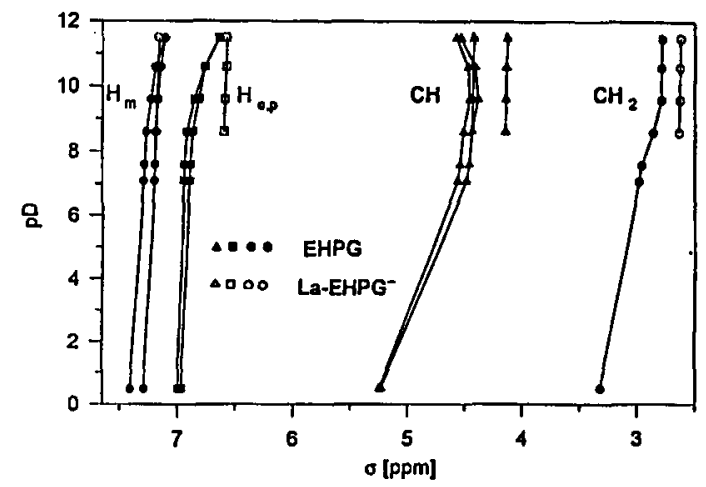

Fig. 3. Calculated hydration number of $\mathrm{Tb}(\mathrm{III})$ for $\mathrm{Tb}^{-\mathrm{EHPG}^{-}}$complex (1:1) depending on pH.

pendence of proton chemical shifts in the system where the ratio of La(III):EHPG equals 1:1. Comparing the values of chemical shifts of nonlabile protons of EHPG ligand with those of La-EHPG- complex, there is observed a substantial decrease in electron density at these protons as the ligand became coordinated. The central atom-carboxylate oxygen bond has an ionic nature and the electron density of nonlabile protons of carboxymethyl groups in the complex depends mainly on an electric potential of the metal ion. Signals of other protons of La-EHPG- complex are observed upfield when compared to those for noncomplexed EHPG ${ }^{4-}$ ion.

Using the PTIR spectra an effect of a rigidity of the complexing system has been studied. On the basis of the FTIR spectra a strength of vibrations of these parts of the ligands, which take a part in complexation, was analysed. The observed shifts of characteristic bands corresponding to vibrations of: $\mathrm{C}^{-} \mathrm{OO}^{-}, \mathrm{C}^{-} \mathrm{O}^{-}$(in aromatic ring) and C-NII, recorded for the EIIPG ligand and Eu-EIIPG- complex (prepared as a solid $1: 1$ at $\mathrm{pII} \approx 11$ ), as shown in Table II, proved a weakening of the vibration bands involving $N$ and $O$ (both carboxylic and phenolic) atoms.

\section{TABLE II}

Chemical shifts of nonlabile protons of ionic forms of EHPG and their changes caused by the dissociation of functional group protons.

\begin{tabular}{l|r|c|c|c|c}
\hline \hline $\begin{array}{c}\text { EIIPG } \\
\text { ionic form }\end{array}$ & \multicolumn{1}{c|}{$\mathrm{pD}^{-\mathrm{CH}_{2-}}$} & $\Delta \delta[\mathrm{ppm}]$ & $\begin{array}{c}-\mathrm{CII}- \\
\Delta \delta[\mathrm{ppm}]\end{array}$ & $\begin{array}{c}H_{\mathrm{o}, \mathrm{p}} \\
\Delta \delta[\mathrm{ppm}]\end{array}$ & $\begin{array}{c}H_{\mathrm{m}} \\
\Delta \delta[\mathrm{ppm}]\end{array}$ \\
\hline $\mathrm{II}_{1} \mathrm{~L}-$ & 0.5 & & & & \\
$\mathrm{II}_{3} \mathrm{~L}^{-}$ & 7.1 & 0.34 & 0.71 & 0.068 & 0.097 \\
$\mathrm{II}_{2} \mathrm{~L}^{2-}$ & 8.6 & 0.028 & 0.055 & 0.024 & 0.013 \\
$\mathrm{IIL}^{3-}$ & 10.6 & 0.002 & -0.020 & 0.085 & 0.030 \\
$\mathrm{I}^{4-}$ & 11.5 & 0.005 & -0.095 & 0.120 & 0.060
\end{tabular}


Energy transfer from $\mathrm{Tb}(\mathrm{III})$ to $\mathrm{Eu(III)}$ in the $\mathrm{Tb}$ (III)-EIIPG-Eu(III) system was studied using the Stern-Volmer analysis of $\mathrm{Tb}$ (III) luminescence quenching $\left(K_{\mathrm{SV}}^{\phi}\right)$ and its lifctime measurements $\left(K_{\mathrm{SV}}^{\tau}\right)$ as a function of the $\mathrm{Eu}(\mathrm{III})$ (quencher) concentration $[Q]$. The values of $K_{\mathrm{SV}}^{\phi}$ and $K_{\mathrm{SV}}^{\tau}$ were calculated from $\mathrm{Tb}(\mathrm{III})$ luminescence intensity or lifetime using the following equations:

$$
\begin{aligned}
& \frac{I_{0}-I}{I}=K_{\mathrm{SV}}^{\phi}[Q], \\
& \frac{\tau_{0}-\tau}{\tau}=K_{\mathrm{SV}}^{\tau}[Q],
\end{aligned}
$$

where $I$ and $\tau$ are the $\mathrm{Tb}$ (III) luminescence intensity and lifetime in the presence, and $I_{0}$ and $\tau_{0}$ in the absence of $\mathrm{Eu}(\mathrm{III})$ (quencher), respectively.

The intermolecular association constant, $K_{\mathrm{C}}$, was calculated from the equation below

$$
\left(I_{0}-I\right) / I=\left(K_{\mathrm{S} V}^{\tau}+K_{\mathrm{C}}\right)[Q]+\left(K_{\mathrm{SV}}^{\tau} K_{\mathrm{C}}\right)[Q]^{2} .
$$

The obtained values of $K_{\mathrm{SV}}^{\phi}, K_{\mathrm{SV}}^{\phi}$ and $K_{\mathrm{C}}$ are presented in Table III. The results show that the energy transfer proceeds dominantly via a dynamic mechanism since $K_{\mathrm{SV}}^{\phi} \approx K_{\mathrm{SV}}^{\tau}$ and the value of $K_{\mathrm{C}}$ is low $\left(K_{\mathrm{C}} \approx 100\right)$, thus proving the monomeric nature of the Tb-EIIPG- complex in the whole $\mathrm{pII}(6-11)$ range studied.

TABLE III

IR spectroscopic data for EHPG and Eu-EHPG- complex.

\begin{tabular}{l|c|c|c}
\hline $\begin{array}{c}\text { Assignment of } \\
\text { vibration }\end{array}$ & $\begin{array}{c}\lambda_{\max }\left[\mathrm{cm}^{-1}\right] \\
\text { ligand }\end{array}$ & $\begin{array}{c}\lambda_{\max }\left[\mathrm{cm}^{-1}\right] \\
\text { complex }\end{array}$ & $\Delta \nu\left[\mathrm{cm}^{-1}\right]$ \\
\hline $\mathrm{COO}^{-}$asymmetric & 1645 & 1595 & 50 \\
$\mathrm{COO}^{-}$symmetric & 1415 & 1395 & 20 \\
$\mathrm{C}-O^{-}$(phenol) & 1175 & 1145 & 30 \\
$\mathrm{C}-\mathrm{NHI}$ & 3380 & 3320 & 60
\end{tabular}

Complexation of the lanthanide ions with EIIPG results in enhancement of lanthanide ion luminescence. We have tested the possibility of applying the spectrofluorimetric method for determination of luminescent lanthanide ions in aqueous solution of the In-EIIPG system. The greatest enhancement of luminescence intensity lias been observed in the system of Dy(III)-EHPG. The luminescence intensity $\left(\lambda_{\mathrm{em}}=578 \mathrm{~nm}\right.$ ) of $\mathrm{Dy}$ (III) was a linear function of its concentration, in the range of $3.3 \times 10^{-7}$ to $1 \times 10^{-5} \mathrm{~mol} \cdot \mathrm{l}^{-1}$, and this system can be applied for spectrofluorimetric determination of Dy(III).

Changes of the luminescence intensity of the $\mathrm{Tb}$ (III) complex and determined hydration number for the Tb-EHPG- complex proved that the EHPG ligand coordinates as a hexadentate ligand. The results show that in the Tb-EHPG- $(1: 1)$ complex the hydration number is $\approx 2$ and therefore the EHPG ligand replaces six water molecules in the inner sphere of $\mathrm{Tb}(\mathrm{III})$ indicating that both the nitrogen donors and oxygen (in carboxylic and phenolic groups) atoms are bonded to the 
metal ion. It is consistent with the ${ }^{1}$ II NMR results obtained from chemical shifts of protons of EIIPG coordinated with $\mathrm{La}$ (III) ions. Also the results obtained from the analysis of the IR spectra proved complexation of $\mathrm{Eu}$ (III) by functional (carboxylic and phenolic) groups and the nitrogen donors.

\section{References}

[1] W.T. Carnal, in: Handbook on the Physics and Chemistry of Rare Earths, Eds. K.A. Gschneidner, L.R. Eyring, Vol. 3, North-Holland, Amsterdam 1979, p. 171.

[2] F.S. Richardson, Chem. Rev. 82, 541 (1982).

[3] J.-C.G. Bünıli, in: Lanthanide Probes in Life, Chemical and Earth Sciences. Theory and Practice, Eds. J.-C.G. Bünzli, G.R.Choppin, Elsevier, Amsterdam 1989, Ch. 7.

[4] W.DeW. IIorrocks, Jr., D.R. Sudnick, J. Am. Chem. Soc. 101, 334 (1979).

[5] S.T. Frey, W. DeW. Ilorrocks, Jr., Inorg. Chim. Acta 229, 383 (1995).

[6] S. Lis, Z.-II. Wang, G.R. Choppin, Inorg. Chin. Acta 230, 139 (1995).

[7] A.D. Sherry, C.F.G.C. Geraldes, in: Lanthanide Probes in Life, Chemical and Earth Sciences. Theory and Practice, Eds. J.-C.G. Bünzli, G.R. Choppin, Elsevier, Amsterdaun 1989, Ch. 7.

[8] S. Lis, J. Ronarski, Z. Innatejko, M. Elbanowski, J. Photochem. Photobiol. A, Chem. 70, 5 (1994).

[0] S. Lis, Z. Hnatejko, M. Elbanowski, Bull. Pol. Acad. Sci. Tech. Sci. 42, 50 (1994).

[10] R. Kiraly, M. Balazs, E. Brucher, Magy. Kem. Fdy. 84, 211 (1978).

[11] S. Salama, F.S. Richardson, Inorg. Chem. 10, 635 (1980).

[12] Z. Stryla, S. Lis, M. Elbanowski, Opt. Appl. 23, 163 (1993).

[13] S. Saliana, F.S. Richardson, J. Chem. Phys. 84, 512 (1980).

[14] S. Lis, G.R. Choppin, J. Alloys Comp. 225, 257 (1995). 